\title{
Rheumatoid Nodule at the Scrotum: A Rare Manifestation of Rheumatoid Arthritis
}

TAESOO CHOI, MD, Department of Urology, Kyung Hee University School of Medicine; HYUNG KYUNG KIM, MD, Department of Pathology, Kyung Hee University School of Medicine; DONG-GI LEE, MD, PhD, Department of Urology, Kyung Hee University School of Medicine, Seoul, South Korea. Address correspondence to Dr. D.G. Lee, Department of Urology, Kyung Hee University Hospital at Gangdong, Kyung Hee University School of Medicine, 892 Dongnam-ro, Gangdong-gu, Seoul 05278, South Korea. E-mail: drpedurology@gmail.com. Ethical approval was not required by the authors’ institution (Kyung Hee University School of Medicine). J Rheumatol 2018;45:1198-9; doi:10.3899/jrheum.171173

Rheumatoid nodules are a common manifestation of rheumatoid arthritis (RA), occurring in 30-40\% of patients and persisting for a lifetime ${ }^{1,2}$. However, rheumatoid nodules in the scrotum are a very rare cause of scrotal masses, even though many kinds of extraarticular manifestations of RA have been described ${ }^{1}$. Our case report details the confusion that physicians experience when encountering rheumatoid nodules in the scrotum.

A 41-year-old man visited our medical center complaining of a right scrotal mass that had been detected a month before the first clinical visit. He had a 5-year history of seropositive
RA managed with prednisolone, leflunomide, celecoxib, and hydroxychloroquine (but not methotrexate), whereby stable low disease activity had been achieved. The patient had also been diagnosed with hypertension 1 month previously and had a smoking history of 20 pack-years.

On physical examination, a paratesticular mass was palpable in the right suprascrotal area. Magnetic resonance imaging scans demonstrated a soft tissue lesion located between the right spermatic cord and penis (Figure 1). Definite histopathologic examination was required to rule out malignancy indicated by features such as an ill-defined

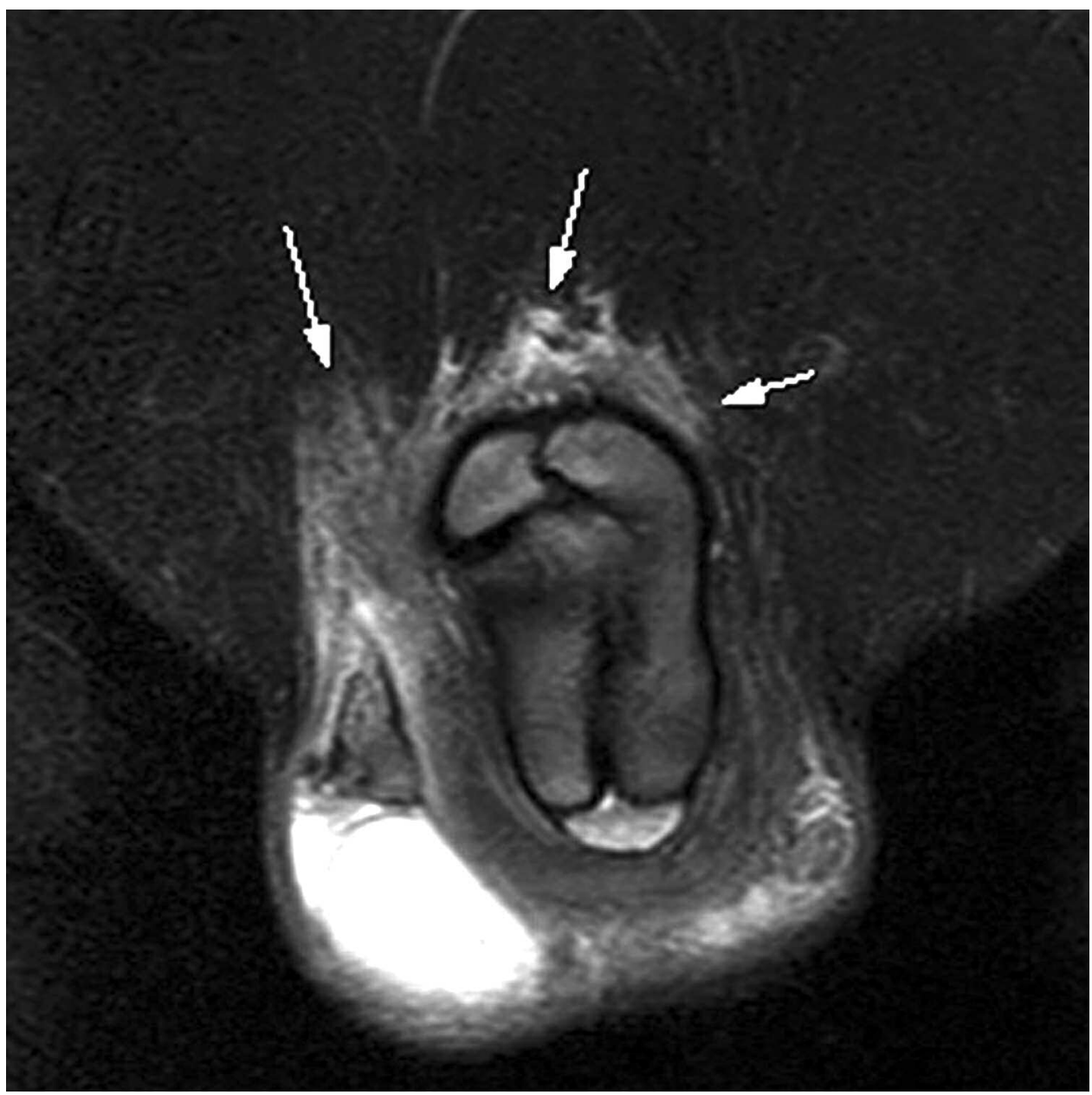

Figure 1. MRI scans demonstrated a soft tissue lesion $6.4 \mathrm{~cm}$ long between right spermatic cord and penis, which exhibited low signal intensity on T1-weighted imaging and slightly high signal intensity on T2-weighted imaging. The mass had an ill-defined margin surrounded the penile root (arrows) and was located along the medial wall of the right scrotum. It involved the subcutaneous layer and fascial layer, but there was no gross invasion of the spermatic cord or corpus cavernosum. MRI: magnetic resonance imaging.

Personal non-commercial use only. The Journal of Rheumatology Copyright (C) 2018. All rights reserved. 


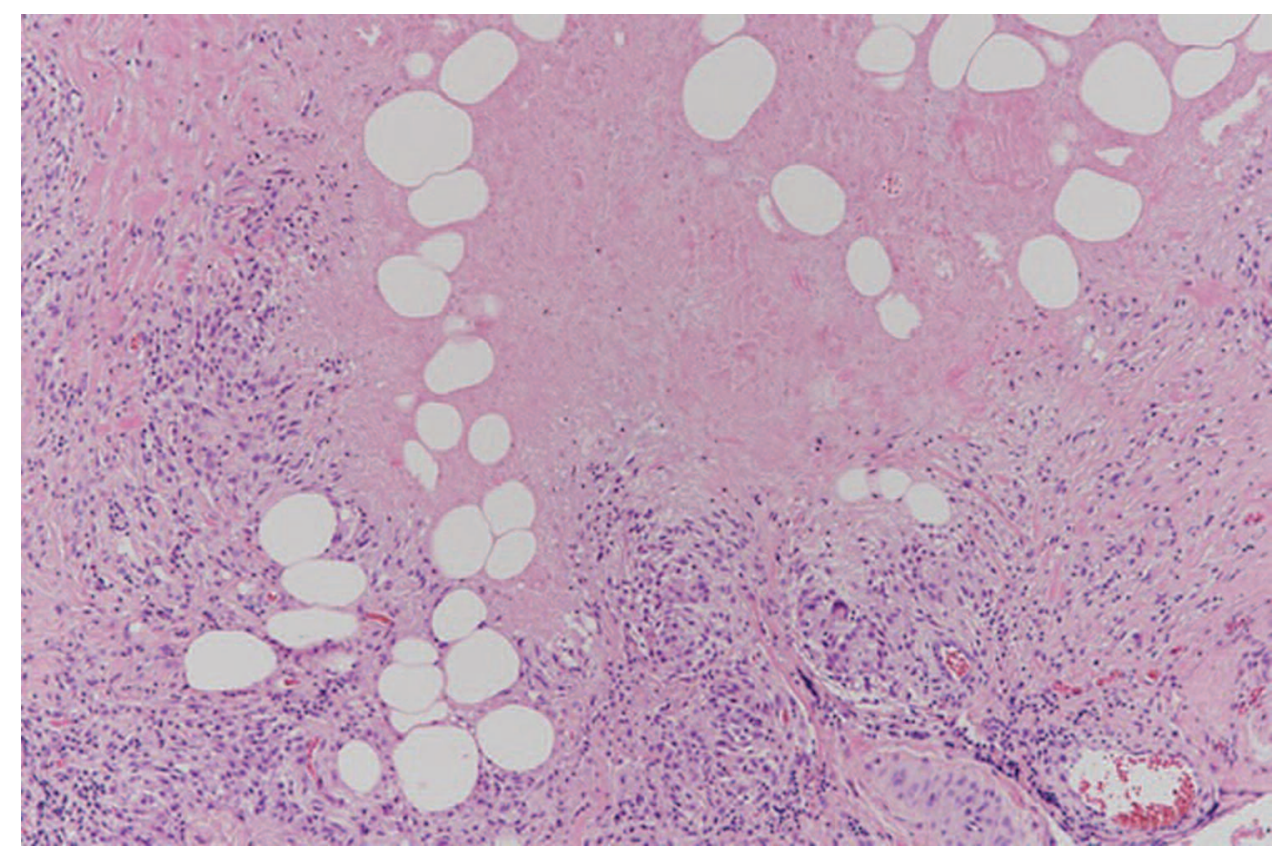

Figure 2. Microscopic findings $(H \& E$ stain, $\times 200$ ) showed multiple necrobiotic foci throughout the specimen, composed of central degenerated collagen surrounded by aggregated histiocytes, as well as multinucleated giant cell infiltration.

margin and infiltration. In further evaluation, chest computed tomography showed irregular subpleural consolidations with ground-glass opacity in the upper lobes, suggestive of rheumatoid nodules.

Excisional biopsy of the mass was performed. The histologic findings were consistent with a rheumatoid nodule (Figure 2).

Rheumatoid nodules in the scrotum should be considered in the differential diagnosis in patients with RA.

\section{REFERENCES}

1. Turesson C, Jacobsson LT. Epidemiology of extra-articular manifestations in rheumatoid arthritis. Scand J Rheumatol 2004;33:65-72.

2. Wolfe F, Zwillich SH. The long-term outcomes of rheumatoid arthritis: a 23-year prospective, longitudinal study of total joint replacement and its predictors in 1,600 patients with rheumatoid arthritis. Arthritis Rheum 1998;41:1072-82. 